\title{
DISTRIBUIÇÃO ESPACIAL E TEMPORAL DA PRECIPITAÇÃO E TEMPERATURA MÉdIA NA REGIÃO DA SERRA DO CADEADO (PR).
}

Fernando César Manosso - fmanosso@utfpr.edu.br

Universidade Tecnológica do Paraná - Francisco Beltrão/PR

Marcio Fernando Gomes

Doutorando - Programa de Pós-Graduação em Geografia - Univ. Estadual de Maringá UEM - Maringá/PR

Alessandro Aoki

Mestre - Programa de Pós-Graduação em Geografia - Univ. Estadual de Maringá - UEM Maringá/PR

Daniele Crislei Czuy Manosso

Doutoranda - Programa de Pós-Graduação em Geografia - Univ. Estadual de Maringá UEM - Maringá/PR

\begin{abstract}
RESUMO: Considerando a carência de estudos sobre as condições climáticas da região da Serra do Cadeado, localizada no setor Norte-Nordeste do estado do Paraná e a influência orográfica direta que esta exerce na dinâmica climática local, este trabalho objetiva fazer uma caracterização da distribuição espacial e temporal das temperaturas e precipitação média acumulada a partir das médias mensais da série histórica das estações climatológicas localizadas no entorno da área, com objetivo de subsidiar novas interpretações e análises sobre a ocorrência da precipitação e da temperatura na área. Os dados indicam que a elevação topográfica e configuração geomorfológica da região influenciam na dinâmica das temperaturas e precipitações médias ao longo do ano.
\end{abstract}

Palavras-Chave: Análise Climática; precipitação pluviométrica, temperatura, Serra do Cadeado, Paraná.

SPATIAL AND TEMPORAL DISTRIBUTION OF RAINFALL AND TEMPERATURE IN THE MIDDLE OF THE SERRA DO CADEADO (PR).

ABSTRACT: Considering the lack of studies on the climatic conditions of the Serra do Cadeado, located in North-East sector of the state of Paraná and orographic direct influence that this has on the local climate dynamics, this work aims to make a characterization of the spatial and temporal distribution of temperatures and rainfall accumulated from the average monthly time series of weather stations located around the area, in order to subsidize new interpretations and analyzes on the occurrence of precipitation and temperature in the area. The data indicate that the elevation topography and geomorphological configuration of the region influence the dynamics of average temperatures and precipitation throughout the year.

Key-Words: Climate Analysis, rainfall, temperature, Serra do Cadeado-Paraná. DISTRIBUCIÓN ESPACIAL Y TEMPORAL DE LA PRECIPITACIÓN Y TEMPERATURA MEDIA EN EL CENTRO DE LA REGIÓN DE SERRA DO CADEADO (PR)

RESÚMEN: Teniendo en cuenta la falta de estudios sobre las condiciones climáticas de la Serra do Cadeado, ubicada en el noreste del estado de Paraná y la influencia directa orográfica que esto tiene en la dinámica del clima local, este trabajo pretende hacer una caracterización de la distribución espacial y temporal de las temperaturas y precipitaciones acumuladas de la serie de tiempo promedio mensual de estaciones meteorológicas ubicadas alrededor de la zona, 
con el fin de subsidiar a nuevas interpretaciones y análisis sobre la ocurrencia de precipitaciones y la temperatura en la zona. Los datos indican que la topografía de elevación y la configuración geomorfológica de la región influyen en la dinámica de las temperaturas medias y precipitaciones durante todo el año.

Palabras-Clave: Análisis del Clima, Precipitaciones, Temperatura, Serra do Cadeado-Paraná.

LA RÉPARTITION SPATIALE ET TEMPORELLE DES PRÉCIPITATIONS $\quad$ ET TEMPÉRATURE AU MILIEU RÉGION DE LA SERRA DO CADEADO (PR)

RESUMÉ: Considérant le manque d'études sur les conditions climatiques de la Serra do Cadeado, situés dans le Nord-Est du secteur de l'État du Paraná et orographiques influence directe que cela a sur la dynamique du climat local, ce travail vise à apporter une caractérisation de la distribution spatiale et temporelle des températures et des précipitations cumulées de la série le temps mensuel moyen de stations météorologiques situées autour de la zone, afin de subventionner de nouvelles interprétations et des analyses sur l'occurrence des précipitations et la température dans la région. Les données indiquent que la topographie d'élévation et de la configuration géomorphologique de la région influencent la dynamique des températures moyennes et des précipitations tout au long de l'année.

Mots clés: analyse du climat, précipitations, la température, Serra do CadeadoParaná.

\section{INTRODUÇÃO}

Entender as características e dinâmica climática de uma determinada porção do território tornou-se uma necessidade no cotidiano das ações da sociedade sobre o espaço geográfico.

Muitos avanços têm ocorrido nas últimas décadas, melhorando a resolução temporal e espacial das análises climáticas em diferentes partes do Planeta, entretanto, sabe-se que ainda existe muito por saber e que extensas áreas ainda não dispõem de base de dados satisfatórias sobre o comportamento dos elementos climáticos.

O clima de uma determinada região da superfície terrestre é determinado por uma combinação de fatores que passa pelas condições de comportamento atmosférico em escala global, regional e local, podendo também inferir, as condições de relevo, posição continental e latitude.

Em 1951, Max Sorre já denominava o clima como sendo um conjunto de estados atmosféricos atuante sobre um determinado local e que havendo uma sucessão habitual destes estados no local, configura-se um clima.

A partir desse conceito, vale ressaltar a importância da análise rítmica sobre o conjunto de dados de um determinado local da superfície, pois somente a interpretação da variabilidade diária dos diferentes comportamentos atmosféricos poderá, em um prazo relativamente longo (firmado por convenção climatológica, mínimo de 30 anos) caracterizar o tipo climático predominante.

Pédelaborde (1970) aponta o "ritmo" como principal aspecto a ser considerado na interpretação do tipo de clima.

Sobre o clima do estado do Paraná, embora inúmeras teses, dissertações e trabalhos de pesquisas de instituições ligadas ao setor tenham promovido uma coleção de trabalhos que resultaram em análises do comportamento climático 
sobre o território do estado, ainda existem áreas que carecem de estudos ou até mesmo uma base de dados históricos suficientemente satisfatórios.

Nesse contexto, esse trabalho objetiva realizar uma caracterização da variação espacial e temporal da temperatura e precipitação na região da Serra do Cadeado, situada na região Norte-Nordeste do estado do Paraná, a partir das médias mensais das séries históricas de dados das estações climatológicas mais próximas e inseridas na área, que são os postos situados nos municípios de Apucarana, Mauá da Serra, Telêmaco Borba, Cândido de Abreu, Ponta Grossa e Londrina.

\section{MATERIAIS E MÉTODOS}

\section{1 Área de Estudo}

A Serra do Cadeado está localizada na região Norte do estado do Paraná e caracteriza-se pela escarpa do Terceiro Planalto Paranaense (Formação Serra Geral), na passagem para o Segundo Planalto (Figura 1), onde afloram arenitos finos, siltitos e argilitos formados respectivamente em ambientes áridos a semiáridos e fluviais (LANGER et al., 2008).

Esta estrutura é fortemente marcada por alinhamentos do relevo no sentido NW-SE, associados à ocorrência de diques, que controlam grande parte das morfologias, produzindo morros com declives acentuados, alinhados nessa direção, e com cobertura pedológica pouco desenvolvida. A hidrografia também se instala aproveitando as fraturas geológicas orientadas nesse sentido.

A cobertura vegetal original que se desenvolveu sobre essa estrutura caracteriza-se por uma transição entre a Floresta Ombrófila Densa, ao Norte e a Floresta Ombrófila Mista, ao Sul, sendo esta última, marcada pela presença de araucárias (IBGE, 1993), sobretudo devido a altitude na região que varia entre 800 e 1200 metros acima do nível do mar.

Essa condição de variação altimétrica também se reflete nas condições climáticas locais. Segundo o SIMEPAR (Sistema Meteorológico do Estado do Paraná) a região possui precipitação acumulada anual média entre 1400 e 1600 milímetros e uma temperatura média entre 18 e $20^{\circ} \mathrm{C}$, com ventos predominantemente de Sudeste.

Ainda sobre o clima da região, segundo a classificação de Köppen (1948) a área de estudo apresenta alguns setores restritos às altitudes de 900 a 1200 metros com o tipo $\mathrm{Cfb}$, caracterizado por um clima temperado úmido com verão temperado, verão e inverno bem definidos, precipitação o ano todo e sem definição de estação seca.

É nessas áreas mais elevadas que o relevo pode conferir especificidades de precipitação e temperatura média, no entanto a baixa densidade de dados climatológicos na região dificulta o entendimento da real influência do relevo no comportamento do clima regional. 


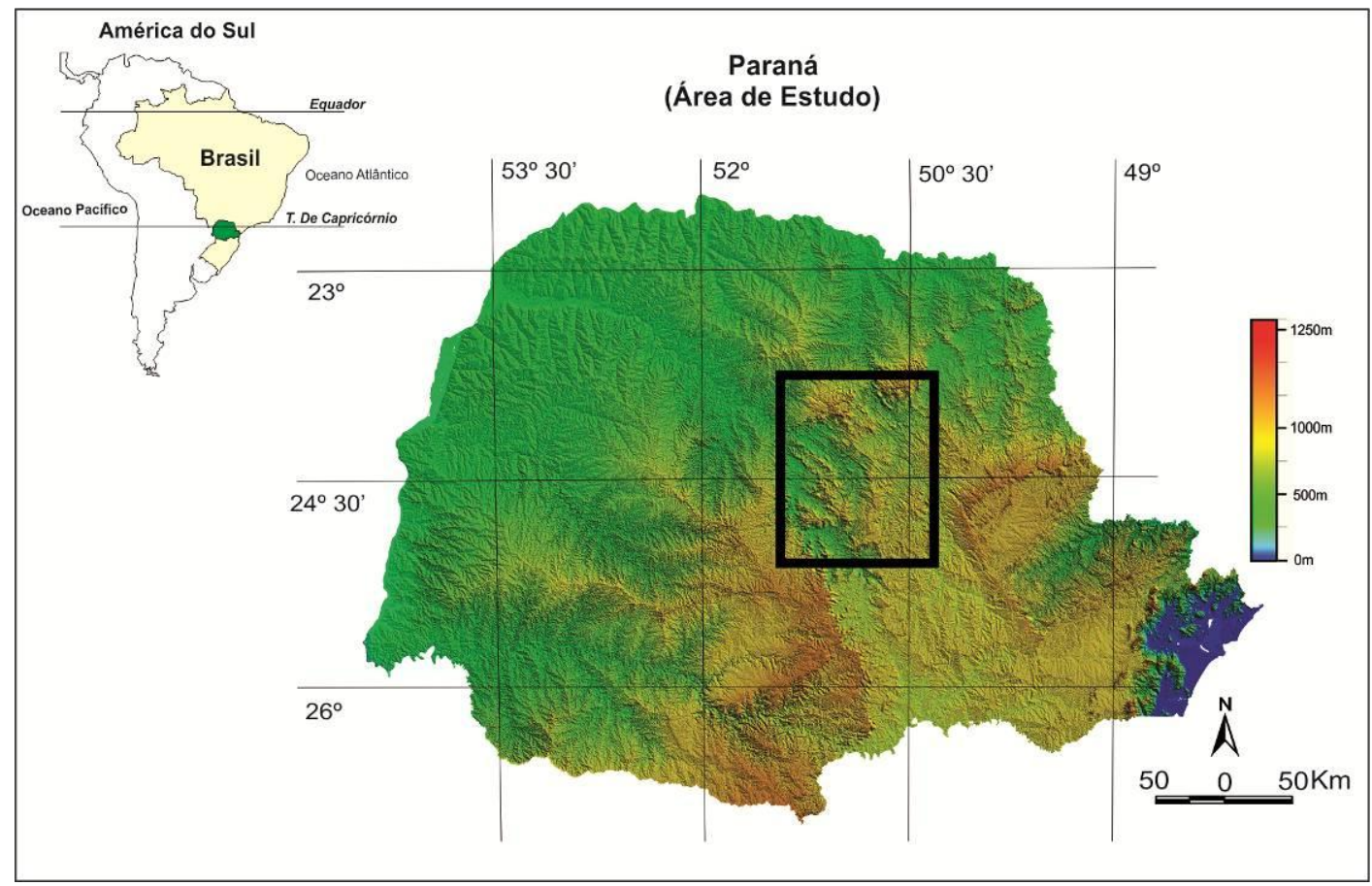

Figura 1. Mapa de localização da área de estudo.

O complexo da Serra do Cadeado abrange parte de vários municípios, dentre eles pode-se citar Mauá da Serra, Tamarana, Ortigueira, Cruzmaltina, Rosário do Ivaí e Faxinal.

Segundo Langer et al. (2008) a região da Serra do Cadeado "encerra importantes afloramentos de rochas paleozóicas e mesozóicas, no contexto das unidades litoestratigráficas que compõe uma sessão do escarpamento jurocretácico da Bacia do Paraná".

Maack (1981) salienta a existência de diques de diabásio que determinam a orientação da linha de serra orientando os principais espigões na região.

Os sistemas econômicos predominantes nos municípios situados na região da Serra do Cadeado caracterizam-se pela atividade agropecuária, com destaque para a produção de grãos nos municípios de Mauá da Serra e Faxinal, enquanto Tamarana e Ortigueira destacam-se pela atividade de produção madeireira, pecuária extensiva e a exploração mineral (argila), como acontece em Ortigueira na produção de cerâmicas para construção civil, além da exploração das placas de arenito das Formações Pirambóia e Botucatu para calçamento ornamental.

\subsection{Procedimentos}

Para alcançar os resultados desse trabalho, foram utilizados os dados da série histórica de temperatura e precipitação (médias mensais) das estações climatológicas do Simepar (Sistema Meteorológico do Estado do Paraná) e Iapar (Instituto Agronômico do Estado do Paraná) localizadas nos municípios de Ponta Grossa, Apucarana, Londrina, Mauá da Serra, Telêmaco Borba e Cândido de Abreu (Figura 2). 


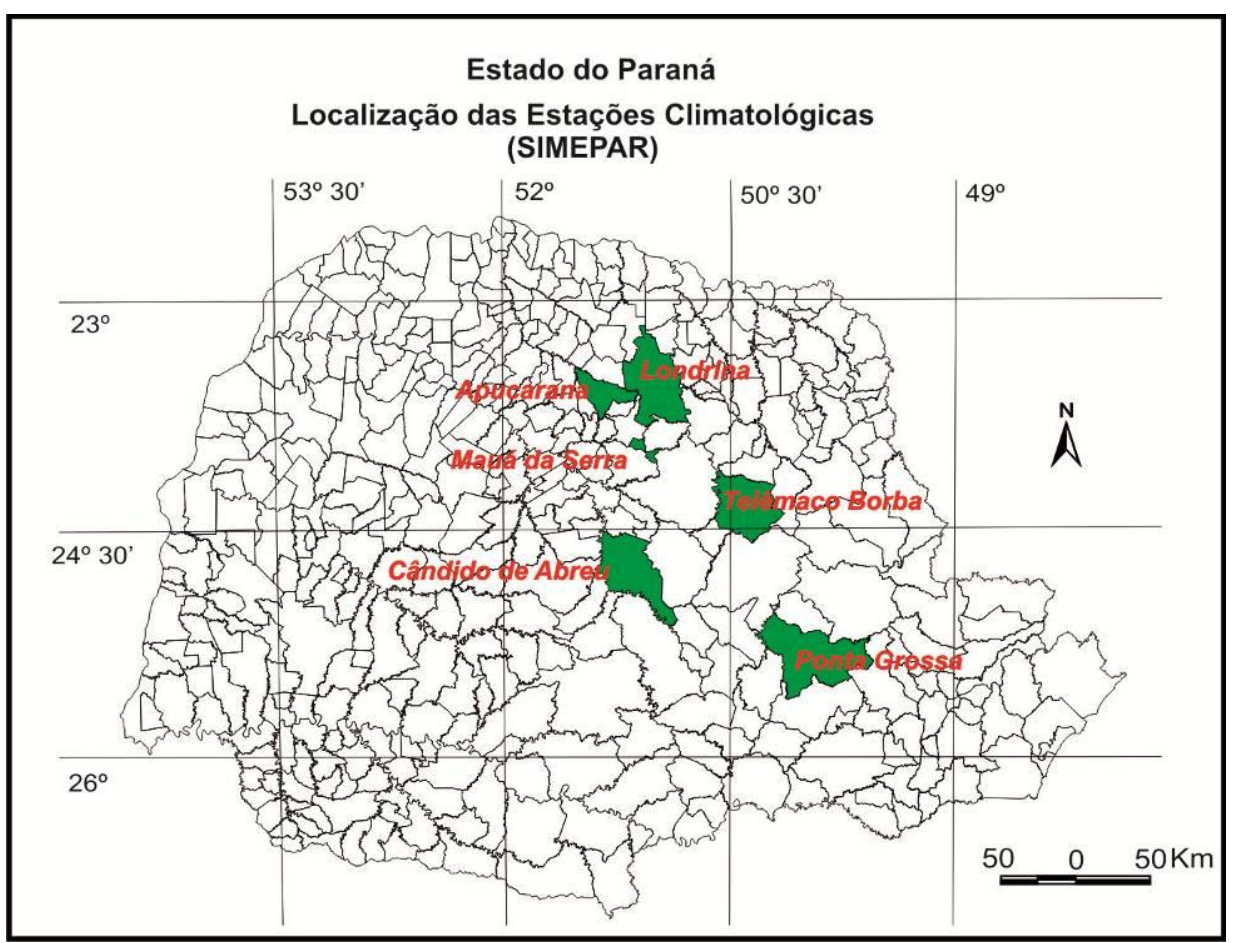

Figura 2. Mapa de localização das estações Climatológicas utilizadas.

Essas estações, localizadas nestes municípios, foram escolhidas por estarem mais próximas da região compreendida pela Serra do Cadeado (Figura 1), com exceção da estação localizada no município de Mauá da Serra que está situada no contexto da própria serra.

O intervalo do recorte temporal das séries de dados históricos de cada estação podem possuir períodos distintos, conforme o Quadro 1, mas a utilização desses dados sem padronizar um recorte temporal único das estações, se justifica pela carência de dados na região e necessidade de uma aproximação das características climatológicas (temperatura e precipitação), objetivo do presente trabalho e que não foi comprometido em função deste aspecto.

Quadro 1. Lista das estações climatológicas, localização, altitude e série histórica.

\begin{tabular}{|lcccc|}
\hline \multicolumn{1}{c}{ Estação } & Latitude & Longitude & $\begin{array}{c}\text { Altitude } \\
\text { (metros) }\end{array}$ & Série Histórica \\
\hline Apucarana & $23^{\circ} 30^{\prime} \mathrm{S}$ & $51^{\circ} 32^{\prime} \mathrm{W}$ & 746 & 1962 a 2002 \\
\hline Cândido de Abreu & $24^{\circ} 38^{\prime} \mathrm{S}$ & $51^{\circ} 15^{\prime} \mathrm{W}$ & 645 & 1989 a 1998 \\
\hline Londrina & $23^{\circ} 22^{\prime} \mathrm{S}$ & $51^{\circ} 10^{\prime} \mathrm{W}$ & 585 & 1976 a 2008 \\
\hline Mauá da Serra & $23^{\circ} 54^{\prime} \mathrm{S}$ & $51^{\circ} 13^{\prime} \mathrm{W}$ & 1.020 & 1979 a 1991 \\
\hline Ponta Grossa & $25^{\circ} 13^{\prime} \mathrm{S}$ & $50^{\circ} 01^{\prime} \mathrm{W}$ & 880 & 1954 a 2001 \\
\hline Telêmaco Borba & $24^{\circ} 20^{\prime} \mathrm{S}$ & $50^{\circ} 37^{\prime} \mathrm{W}$ & 768 & 1976 a 2008 \\
\hline
\end{tabular}

Fonte: Simepar-Iapar. Monitoramento Agroclimático do Estado do Paraná. Médias Históricas. Disponível em:

http://www.iapar.br/modules/conteudo/conteudo.php?conteudo=1070. Consultado em Outubro de 2009.

O tratamento dos dados se deu por plotagem via software Surfer, aplicando o método de interpolação Kriging que permite uma eficiente visualização da 
distribuição espacial das isolinhas de temperatura (isotermas) e precipitação (isoietas) ao longo da área de estudo.

Por se tratar de dados médios, coletados junto aos órgãos informados, não apresentam falhas, portanto não se aplicou técnicas estatísticas para o tratamento das mesmas.

\section{O CLIMA DO ESTADO DO PARANÁ}

Devido a localização meridional do território do estado do Paraná, seu comportamento climático é fortemente marcado pelas características transicionais entre os climas subtropicais e tropicais, evidenciando uma distribuição pluviométrica durante todo o ano.

De acordo com os mapas de isotermas e isoietas confeccionados pelo SimeparIapar, a partir das médias históricas das estações climatológicas distribuídas pelo estado, é possível perceber um gradiente decrescente das temperaturas no sentido NW-SE, associado ao aumento das altitudes e a própria latitude, e um gradiente crescente das precipitações das regiões Norte, Noroeste e Nordeste para a região Sudoeste.

Segundo a classificação climática de Köppen, o estado do Paraná apresenta dois principais compartimentos, sendo um a região central, Norte, Oeste e Nordeste, que possuem o clima tipo $\mathrm{Cfa}$, ou seja, clima subtropical; temperatura média no mês mais frio inferior a $18^{\circ} \mathrm{C}$ (mesotérmico) e temperatura média no mês mais quente acima de $22^{\circ} \mathrm{C}$, com verões quentes, geadas pouco frequentes $\mathrm{e}$ tendência de concentração das chuvas nos meses de verão, contudo sem estação seca definida.

E o outro compartimento é definido pelas regiões mais elevadas (Sul e Sudeste do estado), que apresenta o clima tipo Cfb, ou seja, clima temperado propriamente dito; temperatura média no mês mais frio abaixo de $18^{\circ} \mathrm{C}$ (mesotérmico), com verões frescos, temperatura média no mês mais quente abaixo de $22^{\circ} \mathrm{C}$ e sem estação seca definida.

O estado do Paraná, segundo Nimer (1979) assim como a região Sul do Brasil, possui uma distribuição espacial e temporal homogênea da precipitação e para esse autor, as condições de relevo pouco influenciam no comportamento climático, no entanto, trabalhos de Nery (1996), Silveira (1987; 1996), Silva (2006), Andrade (2003), Sousa (2006), assim como as análises realizadas nesse trabalho demonstram que essa relação pode ser bastante direta.

Uma importante característica da precipitação no estado do Paraná, levantada por Sousa (2006) é que considerando os valores médios de precipitação, nenhuma região do estado apresenta déficit hídrico e que existe um gradiente que aumenta os valores da precipitação no sentido Norte para o Sul do Estado.

Entretanto, as latitudes que compreendem o território do estado fornecem uma condição de transição climática. A presença da passagem do Trópico de Capricórnio representa a possibilidade de condições mais atípicas, com variabilidades interanuais mais presentes (NERY, 1996).

Conforme Andrade (2003), a pluviosidade do estado do Paraná é típica de clima temperado, com exceção da região Noroeste, que possui uma transição para o tropical.

$\mathrm{Na}$ área de estudo desse trabalho, situada em uma porção Norte-Nordeste do estado, compreendendo partes das bacias hidrográficas dos rios Tibagi (a Leste) e Ivaí (a Oeste), divididas pela presença de um grande divisor de águas entre essas bacias, que corta a área de estudo no sentido NW-SE (Figura 3). 


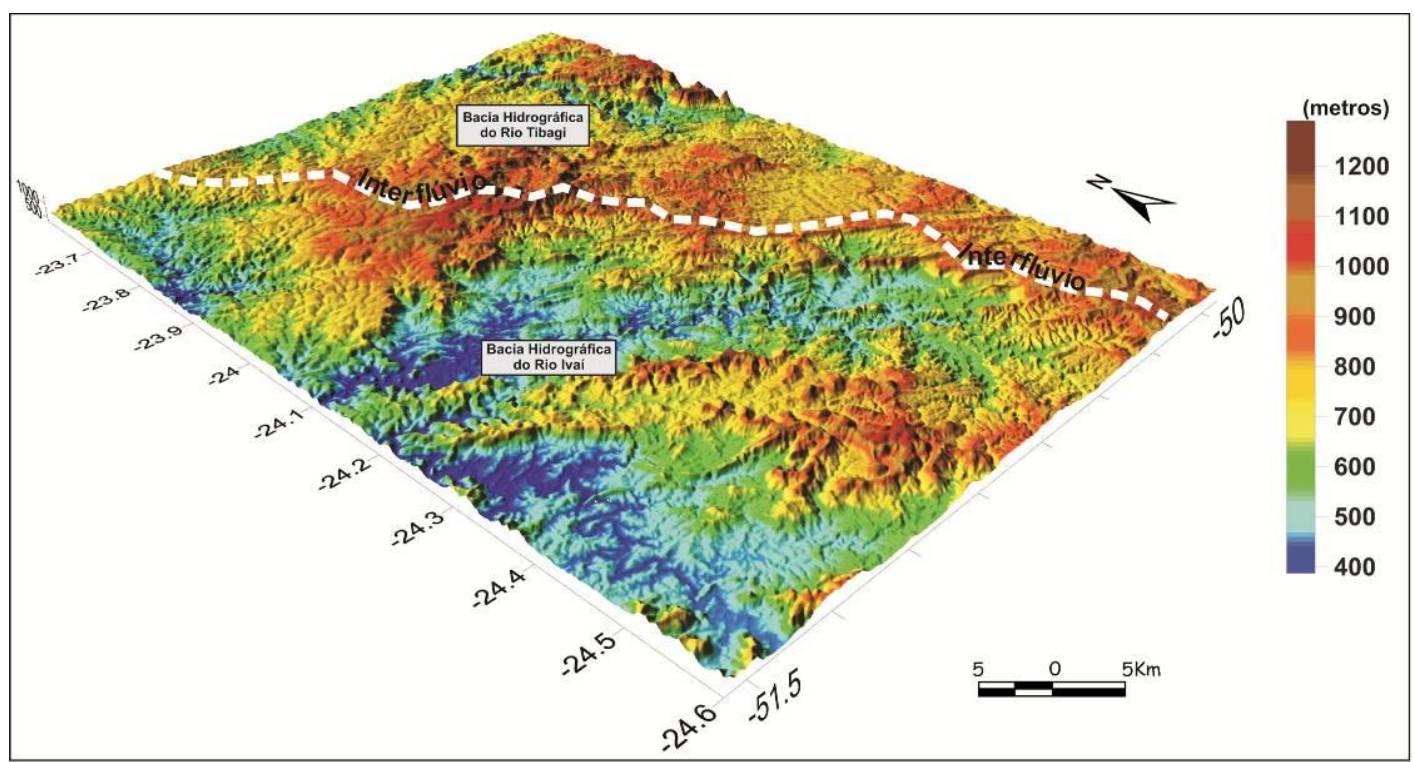

Figura 3. Modelagem Digital do Terreno, Interflúvio principal entre as bacias hidrográficas dos rios Ivaí e Tibagi.

Andrade (2003) verifica que ao longo da bacia hidrográfica do rio Ivaí (setor Oeste da área compreendida aqui), conforme as estações estão em posições de maior altitude, os valores de precipitação apresentam-se mais elevados.

E Silva (2006), ao compartimentar os diferentes setores das regiões Sul e Sudeste do Brasil, no que se refere à precipitação, define os setores das bacias dos rios Tibagi e Ivaí com valores diferentes, sendo a bacia do rio Ivaí com maiores acumulados de precipitação (300 mm a mais em média).

A distribuição das isoietas a partir da média do acumulado de precipitação ao longo da série histórica das estações do estado do Paraná (SIMEPAR) também demonstram os setores a Leste da área de estudo (bacia do rio Tibagi) com precipitações médias acumuladas superiores que no setor Oeste da área. Diferença esta que chega em média a $200 \mathrm{~mm}$, fator esse provavelmente regulado pela topografia do divisor de águas que corta a área no sentido Sudeste-Noroeste.

\section{RESULTADOS}

De modo a apresentar as características gerais do comportamento médio das temperaturas e das precipitações na região da Serra do Cadeado, a Figura 4 ilustra um climograma para cada estação climatológica utilizada, para que se possa observar a relação temperatura precipitação média ao longo do ano.

De acordo com o conjunto de climogramas apresentados na Figura 4, o comportamento geral das médias de temperatura e precipitação vão de encontro a predominância do clima Sub-tropical úmido, pois em todas as estações, os dados demonstram claramente a ausência de uma estação seca, sendo os meses de julho e agosto com menos acumulado de precipitação e os meses de verão, dezembro e janeiro com maior precipitação. 


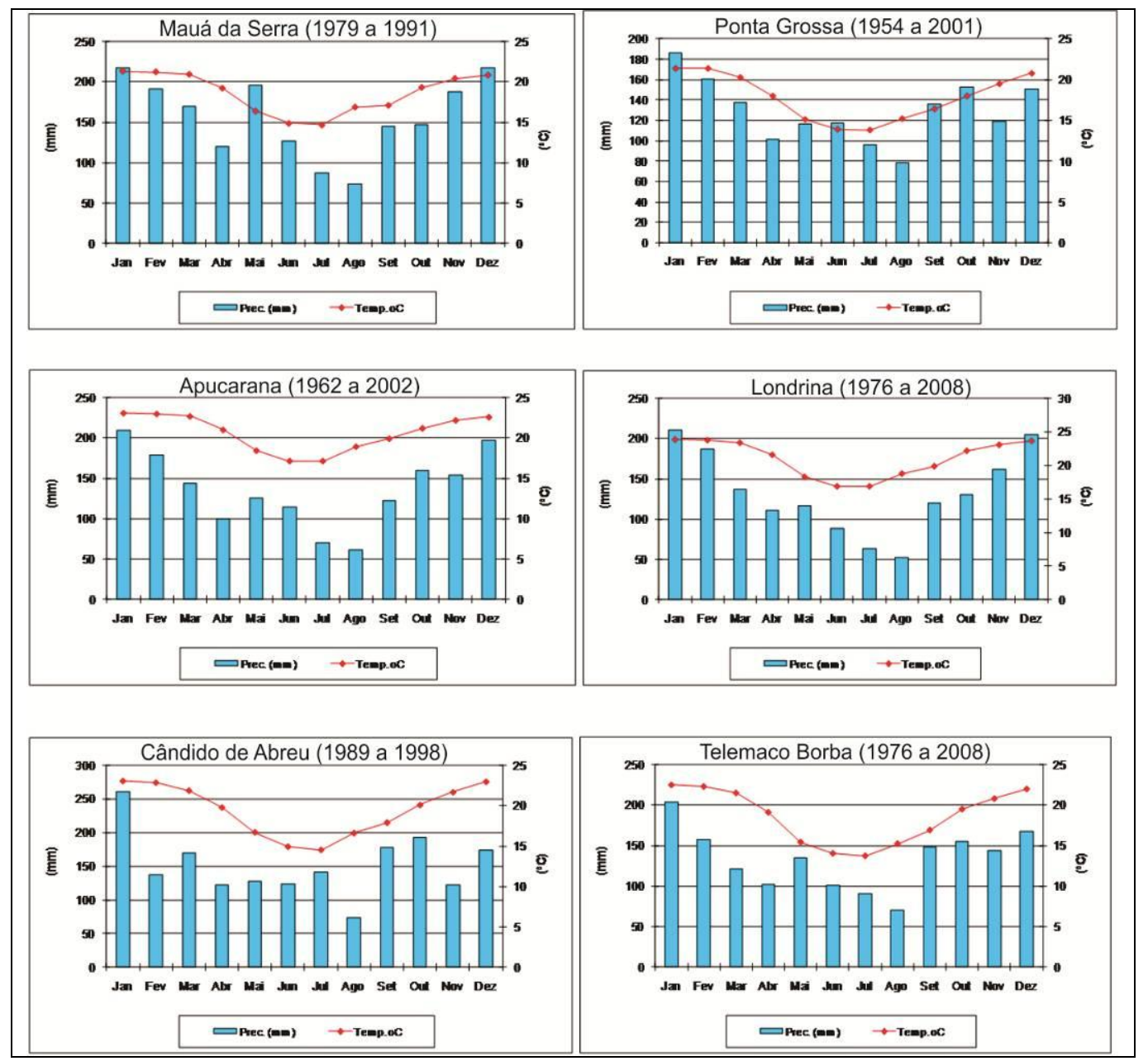

Figura 4. Climogramas da Série Histórica de precipitação e temperatura por estação/município.

Considerando estas duas estações do ano, vale ressaltar entre os climogramas apresentados, a precipitação dos meses mais chuvosos está entre 200 e 250 $\mathrm{mm}$, enquanto que dos meses mais secos, entre 50 e $100 \mathrm{~mm}$, com exceção do climograma da estação situada em Ponta Grossa, que apresenta uma menor amplitude entre os meses mais secos e os meses mais chuvosos, ou seja, apresenta uma precipitação melhor distribuída ao longo do ano em relação as demais localidades.

As médias de temperatura das estações climatológicas estudadas, a partir da interpretação dos climogramas da Figura 4, apresentam-se, em todos os casos com os meses mais quentes dezembro, janeiro e fevereiro e os meses mais frios, junho e julho.

Dois fatores devem ser levados em consideração na interpretação desses dados em conjunto, uma vez que se pretende caracterizar a distribuição temporal e espacial das temperaturas e precipitação nesse recorte de estudo. Uma delas é a diferença de latitude entre os pontos amostrados e as diferentes situações topográficas de cada setor da área de estudo.

Esses dois fatores, combinados podem resultar em importantes respostas às interpretações aqui realizadas, no entanto, a relação direta entre esses fatores, 
com os dados de temperatura e precipitação, embora exista, são de difícil quantificação.

Ainda sobre a distribuição temporal da média de temperaturas, um exemplo que justifica a argumentação metodológica supracitada (Latitude) é o fato das estações de Cândido de Abreu, Telêmaco Borba e Ponta Grossa, na Figura 4, apresentarem as médias mais frias, meses de junho e julho, entre 10 e $15^{\circ} \mathrm{C}$, enquanto que as demais estações, Mauá da Serra, Apucarana e Londrina, conferem média dos meses mais frios, todas acima da casa dos $15^{\circ} \mathrm{C}$.

Nos meses mais quentes (janeiro e dezembro), essa situação já não está muito nítida, uma vez que estações de Telêmaco Borba e Ponta Grossa (Figura 4) com latitude maiores, apresentam média de temperatura dos meses mais quentes do ano superior à estações que posicionam-se mais ao Norte. Nesse caso, provavelmente as condições topográficas das estações podem estar refletindo essa situação.

\subsection{Distribuição espacial e temporal da precipitação média}

A Figura 5 apresenta uma coleção de mapas da distribuição espacial e anual (meses) da precipitação acumulada (média) do recorte de estudo.

Essas isolinhas foram construídas a partir da interpolação dos dados das estações climatológicas supracitadas que se localizam no interior e entorno da área territorial representada.

Observando a distribuição espacial em um conjunto temporal (meses) da chuva média, percebe-se, assim como o próprio mapa de isoietas do estado do Paraná, realizado pelo Simepar-Iapar, a partir das médias históricas de todas as Estações Climatológicas, que há uma concentração das chuvas no setor que compreende a bacia hidrográfica do Rio Ivaí, principalmente nos meses de janeiro, março, maio, junho, julho, setembro, outubro, novembro e dezembro.

Essa concentração pode estar diretamente relacionada a dinâmica imposta pelas condições topográficas do terreno na distribuição das chuvas.

Exemplo disso, pode ser representado pela concentração das chuvas nos meses maio, novembro e dezembro na parte Noroeste do recorte, que coincide com elevadas altitudes (Topos da Serra do Cadeado). 


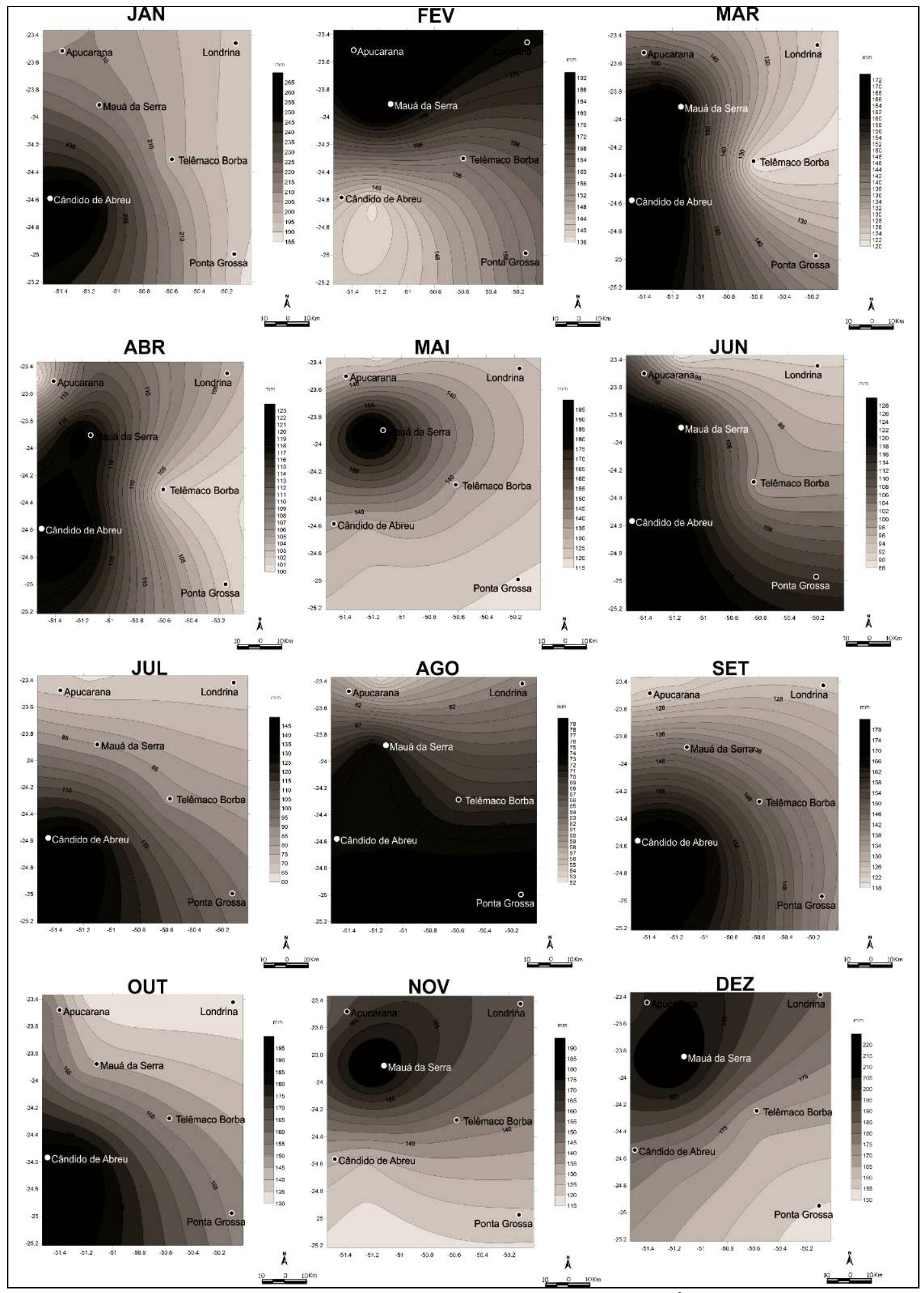

Figura 5. Distribuição espacial e temporal da precipitação média acumulada para a região da Serra do Cadeado-PR. 


\subsection{Distribuição espacial e temporal da temperatura média}

A Figura 6 apresenta a distribuição espacial e anual das médias de temperatura para a região da Serra do Cadeado, por meio das isotermas criadas a partir da interpolação dos dados das mesmas Estações Climatológicas supracitadas, inseridas e no entorno da área de estudo.

É possível observar na mesma figura que existe uma tendência para o aumento das temperaturas médias tanto quando as latitudes são menores, como também, em alguns meses, como janeiro, fevereiro, março, outubro, novembro e dezembro, ou seja, períodos mais quentes, quando é possível perceber a porção Sudoeste da área com temperaturas mais elevadas.

Resumindo, pode-se observar, por meio da análise em conjunto espacial e temporal, que, nos meses mais frios do ano (maio, junho, julho e agosto), as tendências das médias mostram, pelas isotermas que, naturalmente, a região apresenta-se mais fria conforme aumenta a latitude (sentido NW para SE), enquanto que para os meses mais quentes (janeiro, fevereiro, março e dezembro), além dos setores de maior latitude se apresentarem mais frios, os mapas, nesses meses mostram uma convergência de temperaturas mais amenas na porção Noroeste do recorte de estudo, que está diretamente associado à presença de uma área elevada (Mauá da Serra), onde as amplitudes térmicas nesse período do ano não são muito significativas. 

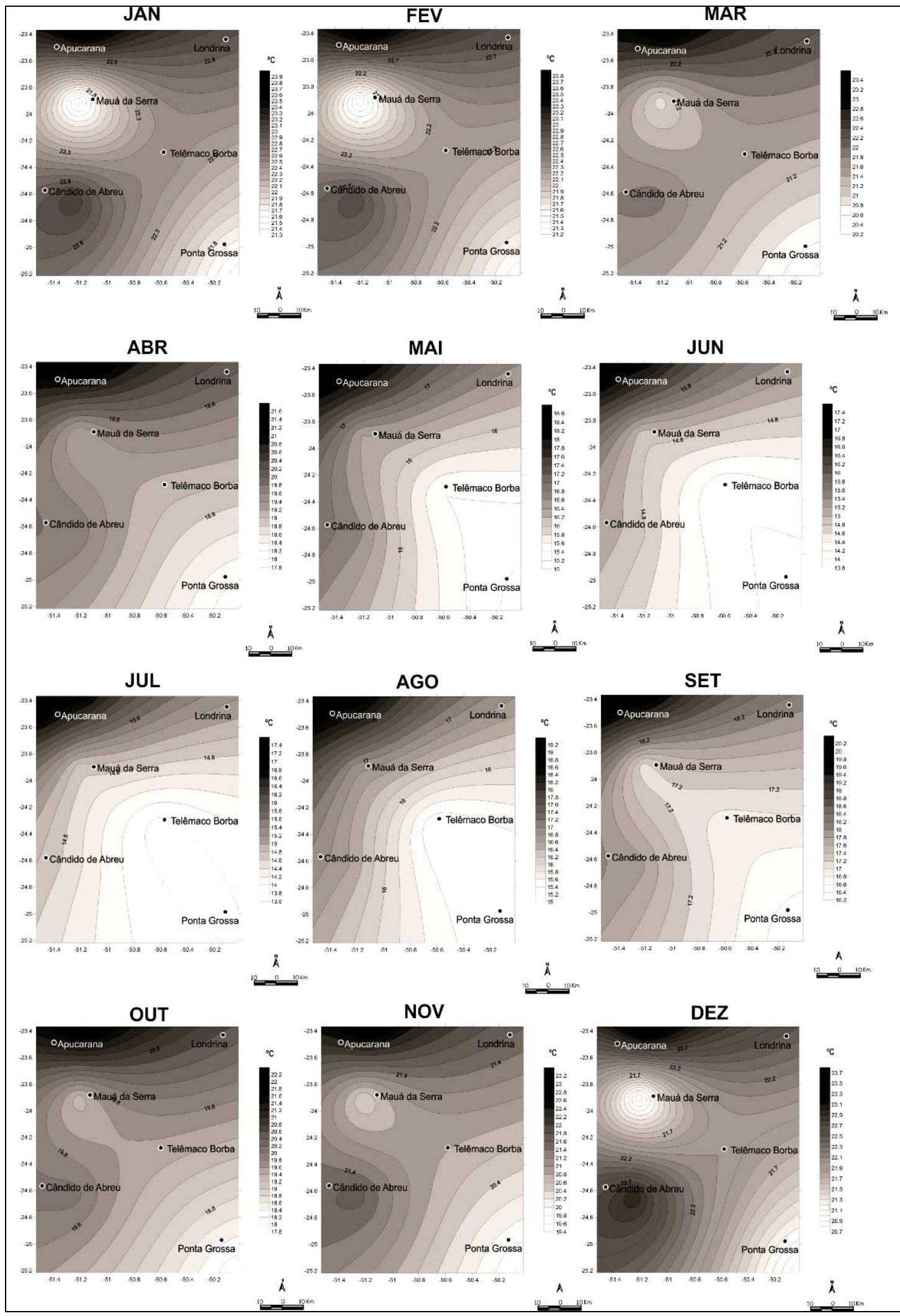

Figura 6. Distribuição espacial e temporal da temperatura média para a região da Serra do Cadeado-PR. 


\subsection{A orientação das vertentes}

Para complementar a interpretação das características da distribuição espacial e temporal da precipitação média acumulada e da temperatura média na região da Serra do Cadeado, confeccionou-se um mapa de direção ou exposição das vertentes da área de estudo (Figura 7).

Esse mapa (Figura 7) representa, com quatro diferentes cores, a direção geográfica que os conjuntos de vertentes estão expostos. Por se tratar de uma extensa área e escala de pouco detalhe, é possível visualizar apenas os conjuntos de setores com direções de vertentes predominantes.

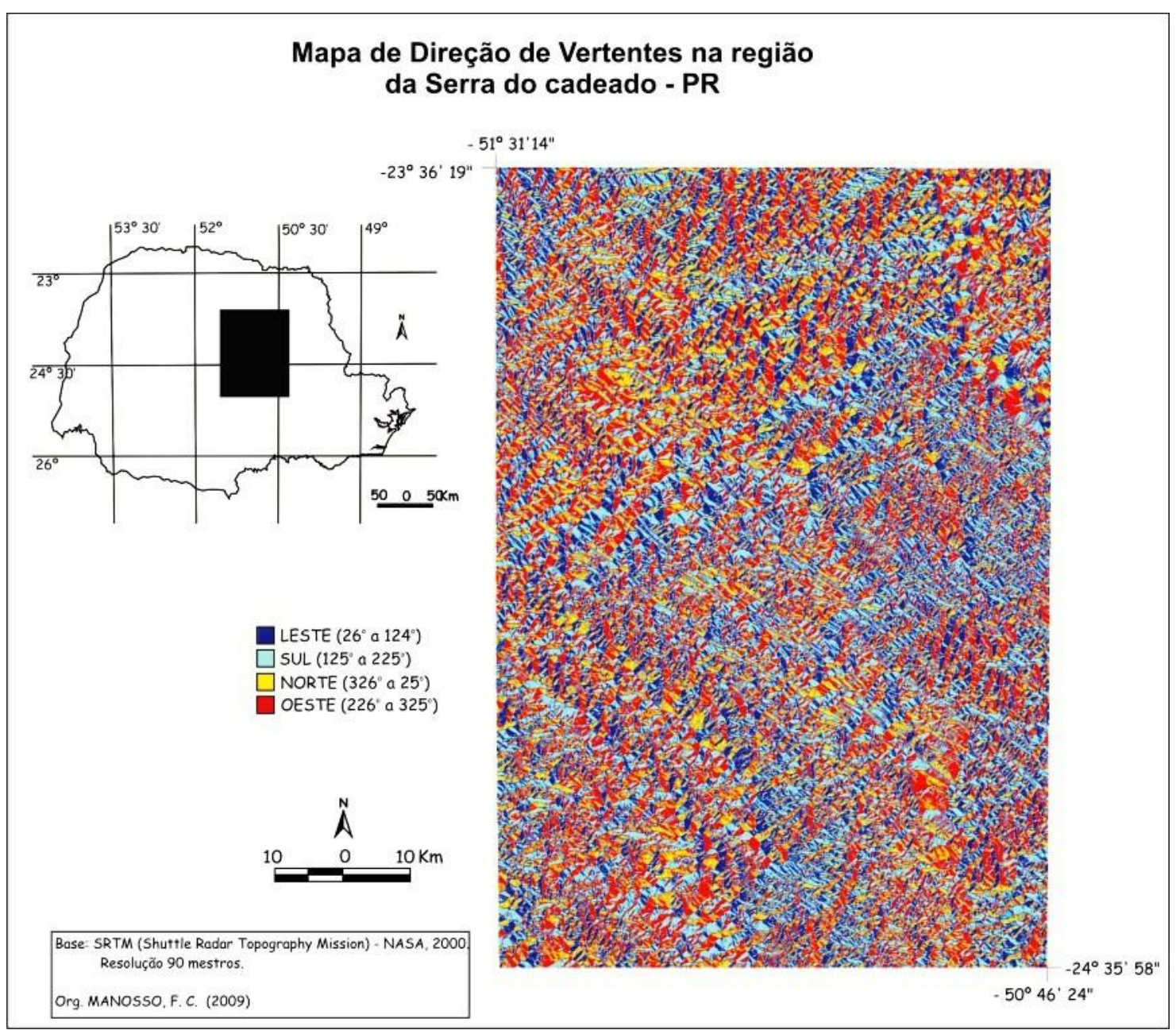

Figura 7. Mapa de Direção das Vertentes na região da Serra do Cadeado.

Assim, de acordo com a Figura 7, tem-se um grande compartimento situado nos setores central, Sul e Sudeste do Mapa, que estão tipicamente caracterizados por vertentes expostas para Sul e Leste. Esse fato, associado à circulação atmosférica regional e as condições de macrorelevo da região, contribuem para a ocorrência de temperaturas mínimas mais expressivas e menor tempo de exposição solar ao longo do dia.

$\mathrm{Na}$ mesma figura, outro setor, situado na porção Norte e Noroeste do mapa, configura um conjunto de vertentes expostas predominantemente para Norte e 
Oeste, fator que contribui para o maior tempo de exposição solar, principalmente no período mais quente do dia e onde as temperaturas máximas podem ser mais significativas que o outro compartimento supracitado.

Não há um número suficiente de estações ou dados para se afirmar, mas certamente essa configuração de relevo, principalmente a amplitude altimétrica e a organização geométrica das encostas influenciam também na própria dinâmica de eventos de precipitação.

Como essa configuração geométrica do relevo influencia diretamente na temperatura, é interessante tentar estabelecer uma relação entre a distribuição espacial das temperaturas médias (Figura 6) e a direção geográfica das encostas (Figura 7). Uma relação poderia ser interpretada a partir das áreas com encostas direcionadas ao Sul correspondendo às áreas de temperaturas médias mais baixas, sobretudo nos meses de abril a setembro. Para outras áreas, onde não há um predomínio evidente de direção de encosta, parece não haver uma relação direta entre essas duas variáveis.

\section{CONSIDERAÇÕES FINAIS}

A partir das interpretações realizadas e técnicas aplicadas, pode-se perceber que a realização desse trabalho alcança algumas contribuições, por meio de alguns indicativos analíticos, sobretudo para o recorte de estudo envolvido, que ainda carece de informações mais detalhadas devido a densidade de dados disponíveis.

Ficou notório que embora a variação de Latitude seja uma regra na análise climática de uma determinada porção da superfície, condicionando fortes mudanças no comportamento principalmente das temperaturas médias, as condições topográficas locais, a sua distribuição, amplitude e organização, combinam informações indispensáveis na análise do comportamento da variação espacial e temporal da precipitação e temperatura atuante.

No caso da região da Serra do Cadeado, os resultados deste trabalho mostram que existe uma combinação, ainda não mensurada, mas importante, entre a variação da latitude, as condições de relevo local e regional na determinação das médias de temperatura e precipitação ao longo da área.

O interflúvio entre as bacias hidrográficas do rio Tibagi e Ivaí limita uma divisão de características da distribuição espacial e temporal da temperatura média mensal e precipitação média acumulada na região da Serra do Cadeado, principalmente no setor da escarpa Serra Geral, onde as altitudes estão entre 900 e 1200 metros, configurando uma anomalia espacial das temperaturas médias nos meses mais quentes (outubro a março).

\section{Agradecimentos}

A Capes pela concessão de Bolsa de estudos, ao Programa de Mestrado e Doutorado em Geografia da Universidade Estadual de Maringá, a Universidade Tecnológica Federal do Paraná (UTFPR, Francisco Beltrão) e a professora Dra Leonor Marcon da Silveira (in memorian). 


\section{REFERÊNCIAS}

ANDRADE, A. R. de. Variabilidade da Precipitação pluviométrica na Bacia Hidrográfica do Ivaí, Paraná. Dissertação de Mestrado - Universidade Estadual de Maringá, PR, 2003, 99p.

INSTITUTO BRASILEIRO DE GEOGRAFIA E ESTATÍSTICA (IBGE), Mapa de Vegetação do Brasil, Escala 1: 5000 000, 1993.

KOPPEN (1948) in MENDONÇA, F. e DANNI-OLIVEIRA, I. M. Climatologia: noções básicas e climas do Brasil. Oficina de Textos, São Paulo: 2007.

MAACK, Reinhard. Geografia Física do Estado do Paraná. J. Olympio, Rio de Janeiro, 1981.

LANGER, M. C, ELTINK, E. BITTENCOURT, J. de S. e ROHN, R. Serra do Cadeado-PR: Uma janela paleobiológica para o Permiano continental Sulamericano. In: Winge,M.; Schobbenhaus,C.; Souza,C.R.G.; Fernandes,A.C.S.; Berbert-Born,M.; Queiroz,E.T.; (Edit.) Sítios Geológicos e Paleontológicos do Brasil. Disponível em: http://www.unb.br/ig/sigep/sitio007/sitio007.pdf. (04/08/2008)

NERY, J. T. Estudio Climático de La Precipitación del Brasil Meridional asociado com fenômeno extrarregionales. Tesis de Doutorado, Universidad de Buenos Aires, 1996, 138.

PÉDELABORDE, P. Introduction a l'éstud Scientifique du clima, París 1970. SILVA, E. S. Variabilidade da Precipitação Pluviométrica nas Regiões Sudeste e Sul do Brasil. Tese de Doutorado - Universidade Estadual Paulista, Botucatu, SP, 2006, 187p.

SILVEIRA, M. L. As condicionantes climáticas e a organização do espaço rural no setor sudeste do Planalto de Apucarana, PR. (Dissertação de Mestrado), v. 1, Presidente Prudente, 1996.

SILVEIRA, M. L. Condicionantes Ambientais da Organização do Espaço Rural no Município de Apucarana (PR). (Monografia de Especialização em Geografia Física do Estado do Paraná) - Universidade Estadual de Maringá Departamento de Geografia, 1987. 131p.

SIMEPAR (Sistema Meteorológico do Estado do Paraná). Monitoramento e Previsão do Clima do Estado do Paraná - Mapas. Disponível em: www.simepar.br Consultado em: 29/05/2003.

SORRE, M. Les fondaments de la Geograpfhie Humaine. (Les fondemensts Biologiques - Le climat) Paris, Armand Colin, 1951.

SOUSA, P. de. Estudo da variabilidade da precipitação no estado do Paraná associado à Anomalia da TSM no Oceano Pacífico. Dissertação de Mestrado, Universidade Estadual de Maringá, Maringá, PR. 2006, 72p. 